\title{
Empowerment of Women in the Era Asean Economic Community (AEC)
}

\author{
Maskur Malaka \\ Islamic InstituteKendari- Indonesia \\ e-mail: Mashur.malaka@yahoo.co.id
}

Accepted: May 20, 2015

Doi:10.5296/ jpag.v5i2.7717 URL: http://dx.doi.org/10.5296/ jpag.v5i2.7717

\begin{abstract}
Female gender has been identified as a domestic worker, of course, requires a great struggle to fit in the commercialization of the world of work. This paper attempts to provide an alternative as part of efforts to improve the professionalism and competitiveness of women Facing Era Asean Economic Community (AEC). Women's empowerment aims as human resources in development, is expected to have professionalism and competitiveness in komersialiasai world of work. Empowerment of women itself is instilling the values that aims to develop self-potential women's dignity and individual (human dignity), be able to help themselves. Empowerment is certainly still involve the public as users of services for women workers, as well as the target group of women empowerment, the expected lack of understanding of the role of women in the era of Asean Economy Community (AEC) which requires professionalism and competitiveness. Therefore, the empowerment that need to be built is public awareness of gender equality, the commercialization of the world of work for women, supporting gender Responship government policy, the optimization of formal and informal education of women, giving space / opportunity and confidence to women to be able to show self-actualization, gave a positive appreciation, and develop skills-based hobby to be able to have creative ideas.
\end{abstract}

Keywords: AEC, quality of work, women 


\section{Introduction}

In the social reality, the phenomenon of women's inability to access the world of work, as well as women's inability to maintain employment in a professional manner, often occurs (Arunima, G. 2003). This is because in addition to the limited employment opportunities for women, there is also a public understanding of women perceive weak so that it appears the stereotype of women as domestic workers (Chaudhuri, M. 2001) .. In addition, the quality and communication skills in filling and maintaining a low employment opportunities ,

The reason women leave work problems such as difficulty communicating about a raise, ask to be involved in a large project, when people doubted his ability, and sexual harassment. As a result of not being able to communicate that, eventually women choose silence, with reason to worry employment would be damaged, felt his culture does not support an open and honest dialogue, feel they have sufficient communication skills, and fear after the talks conducted (Mencher, J . 1988).

The inability of women to access employment and the inability to maintain employment, further marginalizing women from the workforce, due to further revenue opportunities for women in gaining more and more difficult. As individuals, women equally with men have the right to obtain decent employment in accordance with the capabilities and qualities possessed. Understanding of competition obtain employment and competition in the commercialization of the world of work needs to be owned, so it needs to be built professionalism and competitiveness in women. Efforts to reach an understanding on a group of women about the competition in getting a job and keeping a job, should be considered more complex.

In the commercialization of the world of work, women and men alike are required to try and able to carry out the work in a professional and high competitiveness (Mitra, A., \& Singh, P. 2007). Therefore, the demand for quality, and professionalism becomes the main thing. While sociologically, not easy positioning of women equal to men's positions, including in the commercialization of the world of work because of gender role and position in the understanding of different societies. Construction of gender in society have made the roles of men and women are different, and therefore contributes also to the division of labor. To that end, in the build understanding and improve the professionalism and competitiveness against women requires a comprehensive effort in the face of the commercialization of the world of work, especially when faced with the Indonesian state Asean economic community.

Professionalism and competitiveness of women is not only needed in the face of the commercialization of the world of work by a group of men. However, along with men, women should be able to fit into the demands of the Asean Economic Community (AEC) which will begin enacted in Indonesia in 2015. Asean Economic Community is free trade at the level of ASEAN countries, and this will bring a positive influence or negative, on the conditions of employment of the Indonesian state.

Positively ASEAN economic community opportunities to job seekers, to the chance to choose the work in accordance with the interests and quality, in the scope of the ASEAN countries. Currently the countries that entered as a member of ASEAN in addition to Indonesia, 
Malaysia, Singapore, Thailand, Philippines, Vietnam, Brunei Darussalam, Cambodia, Myanmar, and Laos. But negatively, Asean economic community demands this will open a tight competition for job seekers, in addition to aspects of the quality and professionalism of themselves, are also required standard of quality of work of each state job seekers. It would be better if job seekers have the competency standard certification issued by certain training institutions, because of the type of work that is required to obtain the Asean standards are nurses, doctors and accountants (Ministry of Industry, 2014).

Demands for quality and professionalism of work job seekers increasingly considered by business owners (industry), because the demand for the quality and quantity of the products are also taken into consideration business owners. When the Asean free market began to open, the flow of job seekers from abroad were also many flock to Indonesia, so the competition in the face of real-world real work happens. Therefore, improvement of professionalism and competitiveness individually, especially in the group of women needs to be done, with the hope of being able to compete in the commercialization of the world of work alone both at home and abroad, especially in the era of the ASEAN economic community.

Women, as a group of job seekers who have been identified with the type of domestic work, will have more challenges than with a group of male workers in entering the ASEAN Economic Community. The ability of women to have competitiveness in quality compared with men in the global world, a hope.

The involvement of women migrant workers (TKW) abroad over the years, is far from an indicator of the ability of individuals who have the competitiveness and professionalism. Sulistyowati research results (2014) about the construction of identity of women migrant workers indicate that the ability of women migrant workers in idenditas construct themselves in the destination country is low, resulting in women migrant workers vulnerable in trouble in the country of destination. The women migrant workers in addition to minimal education, they do not understand the rules on rights and obligations, do not understand the culture of the country of destination, is also not able to communicate actively with employers, so that the target of resentment employer (Sulistyowati, 2014).

This paper will deliberately try to peel about women's empowerment are required to support the professionalism and competitiveness in the face of the commercialization of the world of work. In general, the goal of women's empowerment is women's development and self-actualization of the potential that exists within him. In general, these efforts can be realized if women were able to see the advantages and disadvantages of potential himself, aware of his position as a gender in society, then consciously seek to develop its potential, either independently or with a group. However, to achieve these conditions the need for measures of women's empowerment models that lead to professional improvement and competitiveness towards the commercialization of the world of work.

Therefore, to build a model of empowerment for women to have the professionalism and competitiveness in the face of the commercialization of the world of work. This exposure will start from discussing the concepts of empowerment, empowerment of women, the social construction of men and women in society (causes and consequences), sexual division of 
labor versus a professional manner, the competitiveness of women facing the commercialization of the work, and empowering women to improve professionalism and competitiveness in the face of the commercialization of the world of work.

\section{Discussion}

\subsection{The concept of Empowerment}

In the concept of empowerment of human resources, defined as a business activity to empower people through change and human development of the ability, confidence, authority and responsibility in the framework of implementing the activities of the organization to improve performance as expected (HasanBisri, 2000). Carver and Clatter Back (1995) defines empowerment as an effort to give courage and opportunity to individuals to take personal responsibility to improve and contribute to the goals of the organization. Shardlow (1998) says that, in essence, the empowerment of discussing how individuals, groups or communities are trying to control their own lives and seek to shape the future in accordance with their wishes. Medium Ife (1995) imposes limits is towards providing empowerment to people over resources, opportunities, knowledge, and skills to improve their skills, determine their future and to participate in and influence the lives of their communities.

Empowerment refers to efforts to enable people, especially vulnerable groups and weak, to have access to productive resources that enable them to increase their income and obtain goods and services they need. Those belonging to vulnerable groups and the weak is, the groups are poor, rural communities, fishing communities, farmers, including women's groups. By gender groups of women are especially vulnerable to obtain violence, discrimination and economic marginalization as a result of the social construction of the genders male and female (gender).

The concept of empowerment of women is the effort to enable women to gain access and control over resources, economic, political, social, cultural, so that women can organize themselves and enhance self-confidence to be able to contribute and participate actively in solving the problem, so as to build the capabilities and concepts self (Decree Women's Empowerment, 2014). Efforts to enable women is run based on the vision, mission and goals of women's empowerment are implemented in programs.

Being the goal of women's empowerment itself include:

1). Improve the status and role of women in the various areas of family life, community, nation and state,

2). Enhancing the role of women as decision makers in achieving gender equality,

3). Improving the quality of independence of the role of women's organizations to preserve the value of unity,

4). Increase the commitment and ability of all institutions that fight for gender equality,

5). Develop empowerment of women, family and community well-being and protection of children. 
The goal of women's empowerment is run based on policy direction and empowerment, as well as measures that have been determined by the Ministerial Decree of Women Empowerment.

Prior to elaborate on efforts to empower women or models to improve the position and professionalism and competitiveness of women within the scope of the commercialization of the world of work, the following will be described in advance about the social construction of women and men in society.

\subsection{Social Construction of Women and Menin Society}

Sociologically, the way people view men and women differently. Man was seen to have more power than women physically, psychologically and intellectually. In the gender concept inherent properties socially constructed, for example, where men are considered more robust, powerful, virile, aggressive, and rational while women are considered weak, soft, pretty, maternal, passive, and emotional (Davis, S. N., \& Greenstein, T. N. (2009). The distinction perspective leads to the distinction the position and roles of men and women in society. So far, the public understands that the role of men in the public domain, was the role of women are in the domestic area. The public role-identikan for men, because men have seen people more rational nature, strong, and responsible as spines family, making it suitable for work outside the household. Medium-identikan domestic role for women, because women are seen to have weaker and emotional nature, have a feminine characteristics (maternal), making it suitable for work in the household.

Distinction of the roles of men and women in the community, eventually gave birth to form sexual division of labor. According to the society, there is a job for men and no suitable jobs for women, where the job requires a masculine trait (physically strong, rugged, bold) is the type of work for men, while jobs that require the feminine (soft, delicate, thorough, neat) is the type of jobs for women. According to Coltrane, S. (2000), in the book Sexual Division of LabourBryant, A. (2003), stated that in Western countries in the decade of the 1980s has developed a very strong views about women in household tasks and men outside the household, only benefit men only. The division of labor that puts women in the realm of households for cooking and raising children makes women do not develop humanly. They become stunted throughout his life because of the very limited space, while men gained space and more opportunity to move in life outside the home and were able to develop themselves optimally (Eagly, A. H., \& Steffen, V. J. 1984).

Gender ideology embedded in the community is the result of social and cultural construction of the role and position of men and women, resulting in sexual division of labor. Sexual division of labor is certainly making each individual has a "narrow space" in determining the interest and the type of work desired. Society has made "job box" suitable for men and "job box" suitable for women. If the "box" is forced to enter the undesired gender group, then gossip or bad comments often arise from people who do not agree. Worse, gender ideology is always socialized society to a new generation, so consequently the type of jobs for women has always been assumed in the domestic sphere and the types of jobs for men in the public domain. 
Differentiation of roles of men and women who have been rooted in society, in gender studies is mainly due to strong patriarchal ideology and socialization of gender values continuously. Patriarchal ideology has become a basic social values and culture. Patriarchal ideology not only serve as guidelines in the family lineage using paternity, but the ideology of patriarchy be decisive in social berkehidupan. In this ideology diutamankan masculine values over feminine values, that men are considered more powerful, more rational, more severe than in women. Women are being positioned weaker, emotional, and two class groups.

Unconsciously thinking that is based on the concept of gender ideology will give birth to forms of gender inequality in the society, especially in women. A lot of work in quality can be done by women and men, but because of people's understanding of different gender then a person can not do it. For example, the type of work leaders, politicians, businessmen, pilots, police, army suitable only for men, was the type of work secretary, treasurer, cook (chef), design clothes, makeup, teachers, nurses, is suitable for women. This type of work is as if the own identity in society according to gender. But along with the progress of time, technology and knowledge society, working areas that should be filled by a particular gender groups, is increasingly filled by individuals who have the quality and professionalism, and are no longer looking at gender.

Progress is to be grateful, gender equality in employment has been in part on the type can be enjoyed by all gender groups. However, to be able to work professionally and have a competitive edge in the face of commercialization of the world of work is increasingly requiring high specialization and commitment, it is not easy for women. Demands cultural role as a house wife who must be able to do all the domestic work of the household, could not be abandoned. In this position of women requires expertise in managing time, self, mind and strength, so that they can run it well. Including commitments by men (partner) should also be constructed so that the cooperation can be achieved.

\subsection{Work division Sexually versus Professional Work}

The world of work, professional work becomes the main element and not the sexual division of labor (gender). Professional work requires the requirement to have the competence or expertise, commitment, confidence, responsibility, and product-oriented. Moderate job based on gender specific (gender) will only give birth to forms of marginalization against a particular gender (female), sexual harassment to a particular gender (female), not product oriented, as well as emerging and inappropriate presumption against a person's job.

There are certain types of work undertaken on the basis of stereotypes of women namely accuracy, neatness and subtlety, but in practice the kinds of jobs that professionally lot was done by men. Examples are beauty salons, makeup artist, designer, cook (chef), and others. The men were involved in the world of work is synonymous with women's skill realized or not it more focused, more professional and better results (satisfactory) of the women's work. (Chowdhury, F.D. 2009).

Groups ofmaleworkersinthisfemalestereotypesare sociallybreak throughthe cagesexual division of laborthathas existedinthe community. Many forms ofinsults, satire, protestagainst 
themmay havefelt, as a resultofgendernon-conformitywiththe typeof work done.But thespirit of hard workandprofessionalismdisplayedbythem, so thatpeople can acceptandmore trust withthe presence of themenwhoworkinfemalestereotypes.

The demands of workandprofessionalismbased onthe quality ofone's work, a requirementtoenter into thecommercialization ofthe world of work. This means thatthe public is increasinglyawarethat theproductivity ofa person's workis notbasedongender, butlabor productivityis determinedby the qualityandprofessionalism ofsomeonewhohascompetitiveness. Therefore, how one behaves, andworkbased oncompetence, commitment, confidence, andthe responsibilityispreferred, bothtomen andto women.

Devika, J., \&Sukumar, M.(2006) explainsthat womenas agendergroupthathasidentititaswiththe type of workthat isbased onfeminist valuescan not alwaysthinkthatkind of workisalwaystohimself. Likewisemen asgendergrouphas an identitywiththe type of workthat isbased onmasculine values(strong, brave, rational), alsocan notthinkthatwomencan not.Along with the changeanddevelopment of society, the kind of workthatcanbe commercializedandcan be exchangedand turning, andcompetedin accordancewithcompetenceandprofessionalismas well as thecompetitivenessof eachindividualboth menand women.

The demands of the world of work that requires quality and profesinalitas need to be prepared, especially for women. In reality many women's groups working world position identical with feminist values, side by groups of men. They tend to do it professionally and maximum. This phenomenon if not anticipated by women's groups, women will be shifted from his own world. Women's groups should be able to improve itself to catch up, behave in a professional manner, working in accordance with their competence, and have self-confidence and the responsibility is high, so it has the competitiveness of the group of men. Group of men capable of filling workspaces women's groups, women's groups should also be able to fill the workspace male group. Competition of this work requires the ability and profesioanlitas each gender group in society. What are the obstacles actually working professional women in the pursuit of competitiveness with a group of men, and how women's empowerment to be able to have a professional work attitude.

\section{4.Women'sCompetitivenessandCommercialization World of Work}

Women are known to have a tendency multitasking attitude, which is able to do several things at the same time. This attitude became one of the advantages for women compared to men, but also at the same time resulting in weakness. With this multitasking attitude, a lot of work that can be completed in a short time, such as in domestic work began to clean the house, take care of the child, preparing meals, can be done in quick time. But the effect of this attitude is likely to lead to a maximum not work, unfocused, and rush in doing the job. Other effects, is physically weak, easily tired and no longer able to do other work to the maximum.

Physically construction of women's bodies are smaller and more fragile than the male body. The composition of the body of the male muscular and bony bigger and stronger, while the 
smaller-boned women's bodies. Caucasian men more harshly, women tend to be more delicate skin. Psychologically, women have an unstable emotional state due to changes in hormone estrogen when menstruating and pregnant. When menstruation and pregnancy, a woman's hormonal condition will rise and will fall back if it was normal. But physically men do not undergo hormonal changes, so psychologically not experience the effect.

Specifically the difference is not to be used as a reason that women are being second only to men, or women are not worthy to have competitiveness in the commercialization of the world of work. This view tends to exist in society in part for this. This view must be stopped, so that women and men have equal opportunities, has a professional attitude and the same competitiveness, both in entering the world of work and in the commercialization of entering the Asean Economic Community (AEC). With the vigorous development of gender studies and feminist ideology which stresses that women need to gain recognition as a whole and objectively, the more aware of all the parties, both groups of men and groups of women to be willing to admit women in terms of quality (Hunnicutt, G. 2009). On the other hand, the gender warriors always voiced at the parliamentary level to fight uplift of women, both of the areas of policy, protection, and access to be able to compete in all areas of life. The Ministry of Women's Empowerment as a locomotive in enhancing the professionalism and competitiveness of women, always create programs to empower women to compete with men in all fields. However this will be futile if the group of women themselves lack the passion to want to fill underdevelopment (Sreenivasan, M. (2004).

From the nature of the work, women are considered to have properties more diligent, more thorough, more presentable, more subtle in doing the work of the laiki men. Perseverance, accuracy, neatness, and subtlety is actually a picture of the ability of women to have the competence, commitment, confidence and high tangungjawab. Hence if this potential is not optimized, either by self women, as well as by the social system and policy makers, then dropping to the women's group will still occur. Not optimal potential of women, due to cultural and ideological systems of gender in society, so that women also tend not aware of its existence. Therefore, there should be an attempt to wake the women to be aware and willing to make efforts through the kindness of women's empowerment strategies.

\subsection{Empowerment of Women to Enhance Professionalism and Competitiveness}

One cause of the powerlessness of women in improving the professionalism and competitiveness is due to differences in people's views on men and women. Differing views on this understanding to encourage the decline of the role and position of women in society, so that women are positioned in a region that is not equitable gender. Gender differences should not be a problem as long as not to present gender inequality. According to Mansour Fakih (1986), forms of gender discrimination against women in the community include: marginalization or economic impoverishment, political subordination, the formation of negative stereotypes or labeling against women, violence against women, and the excessive workload (lots and old), as well gender role socialization unbalanced (Mansour Fakih, 1987).

To help women get out of the slump its role and position in society, as well as the professionalism and competitiveness have to deal with the commercialization of the world of 
work is not easy. Efforts to help women from adversity or referred to the empowerment of women, of course, requires a strategy and comprehensive approach, as well as the cooperation of all parties, particularly the full support of the group of men(socio-cultural) and the policy of both central and local government which Responship gender.

Given the deterioration of the condition of women in Indonesia are caused by factors of people's understanding of gender and cultural aspects, the empowerment should be conducted thoroughly. Some steps for empowerment of women:

1) Efforts to self-realization of women's groups (as the target group) and a group of men (as a group partner), to understand that women and men have the same role and quality in the community, so it needs to be given equal opportunities in accessing education and job training, as well as to fill job opportunities.

2) To change the cultural understanding of gender ideology, through the socialization of gender quality is not socialization of gender ideology. Socialization of gender ideology will further position the group of women in the region number two, which makes the position and role of women in society is limited. While socialization of gender quality, will further motivate women to not give up easily.

3) Develop and optimize the potential and ability of women through various education, training, courses, which support the skills / competencies and skills.

4) Provide space, opportunity, and confidence to women's groups to actualize their potential in all aspects of life, both in the areas of social, economic and political responsibilities and in accordance with the authority given.

5) Provide an appreciation in the group of women in the self-(shows professional performance) in the activities and duties in various ways, so that they increasingly have self-confidence.

6) To improve the competitiveness of the individual in the face of the commercialization of the world of work, should always be given the opportunity in the development of expertise and skills based on a hobby or avocation that can bring creative ideas, as well as involving them in competitions or exhibitions of products.

As noted before, the increase in the professionalism and competitiveness of women in addition to facing the commercialization of the work, as well as efforts to support the Indonesian government in entering the Asean Economic Community (AEC). Where there is free trade at the level of ASEAN countries, and this will influence positively or negatively on the labor conditions of the state of Indonesia both men and women.

The reality of the slump role and position of women in society visible in everyday life when receiving unfair treatment, be it at home, at school, at work, in the organization, or in the wider community. When women are seen low or weak, is not appreciated as appropriate, the gender inequality occurs. Similarly, in the scope of work, women tend to be viewed as weak 
and unprofessional, although the quality may be the same. This perspective affects the confidence of women to be down, and the level of competitiveness is also being dropped. As a result, women are increasingly unable (unwilling) entered in the commercialization of the world of work. Therefore, there needs to be an effort of awareness of all parties, both women, men, and government as the organizer of both central and local state in empowering women.

Responship gender policy is needed to support the optimization potential of women in more professional development and competitiveness. But subjectively women also need to have an understanding of cultural self, that they are disadvantaged by gender position in society. Women are expected to be able to optimize their potential so as to have a professional attitude and competitiveness in the world of work, which eventually able to actualize themselves. But the self-actualization of women still need public confidence to demonstrate professional performance in the face of the commercialization of the world of work.

\section{Conclusion}

1. Justice in part of gender in the type of work has to be enjoyed by all gender groups, but to be able to work professionally and have the competitiveness to face the commercialization of the world of work is increasingly requiring high specialization and commitment, it is not easy for women.

2. Demands the role of cultural (domestic) as a housewife who must be able to do all the domestic work of the household, could not be abandoned. In this position of women requires expertise in managing time, self, mind and energy, so as to run.

3. Work requiring professional requirement to have the competence or expertise, commitment, self-confidence, the responsibility, and product-oriented. Moderate job based on gender specific (gender) will only give birth to forms of marginalization against a particular gender (female) and sexual harassment. Commercialization of the world of work demands would have to be kept away from such a perspective in recruiting job seekers, so proseionalitas and competitiveness becomes primary.

4. The cause of the powerlessness of women in improving the professionalism and competitiveness in the commercialization of the world of work is due to differences in people's views on men and women. Differing views on this understanding in addition to encouraging the decline of the role and position of women in the region are "unfair" by gender, also makes women to be on the "narrow space" that is difficult to create economically, socially, and politically. Gender differences should not be a problem as long as not to present gender inequality.

5. Efforts to empower business activities to better enable or empower power (potency) of people, through change and human development itself, such as the ability (competency), trust (confidence), authority (authority) and the responsibility (responsibility) in the context of implementing the activities -kegiatan (activity) to improve the performance (performance) as expected.

6. Thus the empowerment of women is to provide / improve the capabilities, support / 
build confidence, enables / authorizes, giving a sense of the responsibility in carrying out the activities organized to improve the performance (performance) women as requested by the demands of the working world. Empowerment with efforts to optimize the potential that comes from hobby and support culturally, as well as achieve personal performance through education and provide space for the actualization, the professionalism and competitiveness in entering the working world can be realized commercialization. Thus.

\section{References}

Arunima, G. (2003). There comes papa: Colonialism and the transformation of matriliny in Kerala, Malabar c. 1850-1940. Hyderabad, India: Orient Longman.

Bryant, A. (2003). Changes in attitudes toward women's roles: Predicting gender-role traditionalism among college students. Sex roles, 48, 131-142.

Bryson, B. (1999). "Patriarchy": A concept too useful to lose. Contemporary Politics, 5(4), 311-324.

Chaudhuri, M. (2001). Gender and advertisements: The rhetoric of globalization. Women's Studies International Forum, 24(3/4), 373-375.

Chowdhury, F.D. (2009). Theorising patriarchy: The Bangladesh context. Asian Journal of Social Science, 37(4), 599-622.

Coltrane, S. (2000). Research on household labor: Modeling and measuring the social embeddedness of routine family work. Journal of Marriage and Family, 62, 1208-1233.

Davis, S. N., \& Greenstein, T. N. (2009). Gender ideology: Components, predictors, and consequences. Annual Review of Sociology, 35, 87-105.

Dessler, Gary (2000): Human Resource Management, International Edition, 8th Ed. Prentice Hall, Inc., Upper Saddle River, New Jersey

Devika, J., \&Sukumar, M. (2006). Making space for feminist social critique in contemporary Kerala. Economic and Political Weekly, 41(42), 4469-4475

Djajanegara, Soenarjati. 2003. An Introduction toFeministLiteraryCriticism. Jakarta: PT GramediaPustakaUtama.

Eagly, A. H., \& Steffen, V. J. (1984). Gender stereotypes stem from the distribution of women and men into social roles. Journal of Personality and Social Psychology, 46, 735-754.

Fakih, Mansour,1986, ShiftsConceptionGenderandSocialTransformation, Yogyakarta: PustakaPelajar.

Hunnicutt, G. (2009). Varieties of patriarchy and violence against women: Resurrecting "patriarchy" as a theoretical tool. Violence Against Women, 15(5), 553-573.

Istibsyaroh. 2004. Women'srightsGenderRelationshipsAccording toTafsir Al-Sya"rawi. Jakarta: Teraju. 


\section{Macrothink Institute ${ }^{\mathrm{TM}}$}

Kemenperin

2014

Indonesialatein

theface date29 Dec 2014.

Mencher, J. (1988). Women's work \& poverty: Women's contribution to household maintenance in South India. In Daisy Dwyer \& Judith Bruce (Eds), A home divided: Women and income in the Third World (pp. 99-119). Palo Alto, CA: Stanford University Press.

Mitra, A., \& Singh, P. (2007). Human capital attainment and gender empowerment: The Kerala paradox. Social Science Quarterly, 88(5), 1227-1242.

Riza, RisyantidanRoesmidi. 2006. Community Empowerment. Sumedang: AlqaprintJatinangor.

Sreenivasan, M. (2004). Conjugality and capital: Gender, families, and property under colonial law in India. Journal of Asian Studies, 63(4), 937-960.

Veithzal, Rivai. 2005. Human Resource ManagementFromTheorytoPractice. Jakarta: PT. Raja GrafindoPersada 